\title{
Media Construction of Social Reality and Communication Impact on an Individual
}

\author{
Denis Chistyakov ${ }^{1, *}$
}

\begin{abstract}
${ }^{1}$ Hotel Business and Tourism Institute, Peoples' Friendship University of Russia (RUDN University), 6 MiklukhoMaklaya Street, Moscow 117198, Russian Federation

*Corresponding author. E-mail: chistyakov.d@gmail.com
\end{abstract}

\begin{abstract}
The author discusses the basic principles of constructing the world with modern digital media, as well as the ways and forms of media impact on people. The researcher considers the possibilities of professional communicators in creating artificial, simulative images of the world, perceived as real and objective. The article presents Niklas Luhmann's concept of media as an autopoietic system and Jean Baudrillard's view on media as "noncommunication". The forms of visual influence of televised information on the human being and society are shown.
\end{abstract}

\section{Keywords: philosophy of mass media, media impact on a person, social construction, mass communication}

\section{INTRODUCTION}

The issues of the impact contemporary mass media have on an individual and society are determinant in the study of their activity and significance. Theoretical analysis implies the establishment of cause-effect relations where the cause of a phenomenon is the information coming in various forms through various means of communication. Historical structures of messages transmission witnessed the transformation and development from the very first printed papers into new digital products. Yet, their enormous impact on public and personal life has always been undoubted. Quite often, media impact has changed legislation, shaped public policy, caused social unrest, and protests.

Gradually, the social belief regarding media has formed. It states that it is vital to protect not so much ourselves but some abstract others, more exposed to an influence. Researchers have called this phenomenon the "third-person effect" [1]. People tend to believe that some other consumers are more exposed to the negative influence of and are more susceptible to instilled various models of action, including violent ones. Manifestations of the described effect are more typical among the bearers of public opinion who understand the influence of mass media (primarily television) almost literally - as sowing in the human consciousness the images of the world, behavioral patterns, verbalized judgments, choices of lifestyle, etc. At the same time, some viewers are convinced that it is they who may avoid the adverse effects and take on the functions of

*Fund: The reported study was funded by RFBR and MOST according to the research project № 20-511-S52002 "Philosophy of Being Human as the Core of Interdisciplinary Research." keepers of public morality. However, this kind of concept of everyday life doesn't correlate with the direct impact of messages on an individual's consciousness.

This article deals with the actual concepts of media impact on a person in their process of constructing a social reality, which, in turn, acts as an unreal and unbiased world.

\section{SOCIAL CONSTRUCTION OF REALITY AND N. LUHMANN'S CONCEPT OF AUTOPOIESIS OF MASS MEDIA}

We should mention that academic research doesn't deny the enormous influence of media on people but instead tries to establish the degree of such, its character, social, and cultural factors that walk alongside. Numerous results belong to various directions and schools, sometimes complementing and sometimes contradicting each other. However, there is also a shared point for many academics. It is as follows: the impact of media on public and individual consciousness is a complex, indirect, profound process that has many components, among which are psychological, socio-cultural, educational factors, technological and content goals, and objectives of editorial offices.

As means of communication develop and become increasingly complex, the nature of impact they execute on people and society also changes, which entails a corresponding transformation of views and approaches to the study of this crucial social phenomenon. Let us consider how qualitatively the new media influence our contemporaries, taking into account the occurring 
structural changes, factors of spectacle, audio-visuality, and the ritualization.

We proceed from the thesis that modern media have reached the state of an independent social system functioning as a particular institution with its specific mechanisms of internal life and external communication with society and social groups. Thus, media in modern society have an autopoietic nature i.e., of an autonomous isolated, self-organizing, and self-sustained system. Communication processes, which may vary in their character throughout the ages of traditional and new media, provide the autopoietic nature. Still, the general structural model - "message, information, recipient and their understanding" - is preserved.

The German sociologist Niklas Luhmann elaborated on the concept of autopoiesis of postmodern society and communication. He writes: "System is autonomous not only at structural but also at operational levels. This is what the concept of autopoiesis means" [2]. In previous modern societies, especially traditional ones, there was no autonomous self-organized system with internal uncertainty which its structures eliminate.

Media, as an autopoietic autonomous holistic system, inherently postmodern, and performing their functions within modern society, is in the constant and uninterrupted transmission of information and is inseparable from society itself. A continuous process of information transmission serves as a criterion of the existence of the communication system as a specific and independent subsystem of society.

When considering the impact of media on society and an individual, we shall proceed from the following general provision. Through the continuous transmission of information, media construct and structure reality and socio-cultural dimension. With the establishment of screen culture, allowance of television and information and delivery technologies to the construction of social reality, the factors of entertainment and visuality started playing a significant role. Appeal as a principle of visual communication is naturally and deeply embedded in the images of reality.

However, it would be quite reckless to believe that media construct social reality per the principle of objective coverage of current events. Indeed, public opinion generally tends to trust the objectivity of broadcast news. The news stories aired by television are presented to the viewers in a prompt manner and, therefore, in an undistorted way. Niklas Luhmann disappoints viewers with the following criticism of the nature of news: "Reality interests media only marginally. The problem, therefore, is not the truth but the inevitable and also the desired and controlled selectivity. To the same extent that geographical maps, in terms of their volume and detail, correspond to actual territory $\langle\ldots\rangle$ it is just as incredible and mutually agreeable between operational and representable reality" [3].

Luhmann argues that by implementing the selective factor of information to be broadcasted as news or commentary on a video, communicators are guided by the requirements of surprise and novelty, maximum accessibility, and "local orientation." In the so-called freedom of information, preference is given to coverage of conflicts and scandals, violation of moral norms, law, and political correctness. Even the requirement of relevance causes to priority coverage of tragic events, accidents, crashes, etc. These factors not only increase the resonance in the society but also lead to a deficient degree of objectivity of the presented material. Broadcasted images, news stories, constructed models of the world around are very far from reality and have nothing to do with the truth.

\section{VISUAL MODELING OF THE WORLD BY DIGITAL MEDIA: THE EXCLUSION OF THE HUMAN BEING}

In the era of screen culture, media are reshaping the demands of the times, changing the way of presenting, including the visual language of movies and TV. The processes of updating mass communication steer to inevitable internal changes in the model of relations "communicator - means of screen communication message - recipient." The creation of information for further broadcasting utilizing reception and processing of new message flows based on spectacular visual images determine essential features of postmodern culture.

A new stage in the development of screen culture is related to the strengthening of television and digital broadcasting. Television occupies a unique position in the whole system, which makes it possible to reconstruct the internal dialogue of the TV audience. The Russian researcher P.E. Schultsman notes that now there is such an epoch of mass communications development, during which "a screen-based means of mass communication form techniques that allow modeling [italics by the author - D.C.] the process of human perception of the world around" [4]

Modern digital TV provides information with a visual and spectacular character. As a result, screen images appear like the picture of the world created by television and then broadcasted to consumers. Through visual images, a recipient perceives the world with the certainty that the latter is the fruit of his efforts. In this respect, the exchange system is unidirectional: only the media are involved in the transmission of messages. At the same time, a person is excluded from this type of communication. 
The French philosopher J. Baudrillard emphasized the peculiarity of interaction in communication, that, according to him, carry out noncommunication. In his article Requiem for the Media, he writes:" A distinctive feature of media is that they are <...> anticommunicative - if we accept that the definition of communication is an exchange, a space of words and answers, and, consequently, a responsibility... Mass media $\langle\ldots\rangle$ are that which forever forbids the answer, which makes the process of exchange impossible (save in the forms of a simulation of an answer) $<\ldots>$ in the sphere of mass media something is being said. Everything is done in such a way that no answer is given to these words" [5].

Usual traditional communicative influence is an interdependent process of subject-object relations. When media influence a person, they also disturb the interaction, the effect is thus unilateral, and the action of the subject is exaggerated without receiving feedback. Of course, it is possible to talk to a TV, but you are not getting a response, it is a conversation with self. Media are silent in this respect, and they do not pay attention to the consumer of their information products. The problem is that people often perceive biased images of the world as their own that do not correspond to objective reality.

In shaping the models of the world that are being broadcasted to recipients, newsworthy information becomes a significant component because of its presentism, rapid dynamics, and seemingly objective content. Among all forms of data, transmitted news is historically the youngest phenomenon of the mass communications system and one of the leading and popular genres of journalism. News reports in modern communications take on an institutional character because it instantly reflects events through digital communication and symbolizes some participation of people through co-participation in recent events, incidents, or tragedies occurred.

We should note the following pattern. If broadcasted news and the visual images accompanying them coincide with people's expectations or perceptions, which in turn are caused by previous experience and knowledge, then such a meaningful coincidence becomes a social fact and obtains social meaning. Media thus may influence individuals in the formation of all sorts of identity (from personal ethnocultural to civic one), to present a designated image of the world, similar to the one already existing in the views of a recipient [6].

Since the advent of television, the spectacular component has become a significant structural element of news, social, and sports coverage. Created footages thanks to the developing technological means and improved methods of cameramen's art, claim to create integral television images, equal to the picture of a recipient's world. The spectacular context of broadcasting contributes to the fact that the designed media product establishes a model of the world, comparable or similar to the vision already existing in the mind of a recipient.

In the digital era, the spectacular component becomes even more significant. Passing through the phase of digitalization, spectacle acquires the specificity of television language and is being transformed depending on the specifics of a medium. The nature of mass media interprets, distorts information so that it cannot be embedded in the existing social and political system, or correspond to the aims of the transmitter. We may argue that with the emergence of new technologies, the world around the human being, of which they learn from outside sources, is a world designed by professional communicators. Everything we know about the current events we learn from media [7]. The power of digital sources is that they have a hugely symbolic and conceptual power providing a proxy function among communicators and recipients in the informational space. Producers select the information they process in the appropriate format, decide which facts to cover and which to overlook, and how to set priority depending on the type of information. These and many other methods for preparing coverage make it possible to view media as constructors of social reality.

Constructed images and models of the world belong to the unreal, biased, illusive, simulated sphere. Yet, professional communicators finetune constructions to such a degree of perfection that in the views of individuals, they coincide with the image of the real world. The American researcher E. Epstein stresses from the study of news production by American media corporations that their products do not reflect objective reality but construct it by implementing the established production model. The model's fundamental principle is the continuation of transmission activity "at any cost," whether it concerns TV or audio recording [8]

To a large extent, the perception of produced messages as reality is facilitated by the fact that modern information transmitters use such means that can be considered ritualized and institutionalized. We would like to point out that the transmission of messages is a self-sufficient, autopoietic process in which communication between senders and recipients is unidirectional, and there is no meaningful feedback. Satisfying the needs and demands of information consumers as well as objective targeting of the target audience is problematic here. In essence, the content and form of messages depend mainly on the objectives of producers, respected owners, the need to obtain a specific public opinion, etc. Such a model allows media to freely cooperate and interact with other social institutions such as political and economic ones. 


\section{CONCLUSION}

When considering the impact of media on society and individuals, one cannot, of course, absolutize the idea of the total effect and just the negative consequences. However, it is also impossible to ignore the results of research on the harmful effects of constant and continuous torrents of information on a person. The media influence is controversial and ambiguous, with multiple and diverse approaches to studying the phenomenon. It seems to us that the French philosopher Jacques Rancière grasped most clearly this contradiction and the multivalued impact on the perception of society and individuals. He writes: "We must challenge the received opinion that this system drowns us in a flood of images in general, and images of horror in particular, thereby rendering us insensitive to the banalized reality of these horrors. <...> If horror is banalized, it is not because we see too many images of it. We do not see too many suffering bodies on the screen. <...> The system of information does not operate through an excess of images but by selecting the speaking and reasoning beings who are capable of 'deciphering' the flow of information about anonymous multitudes" [9].

Contemporary communicators, qualitatively changed with the advent of the generation of digital technologies, are a self-sufficient institution that widely uses spectacular, audiovisual means, factors of ritual transmission in the process of preparing and transmitting the information. All of the factors allow us to say that in modern society, mass media construct the social reality, structure the cultural and political space of the society.

\section{References}

[1] Davison, W.P. The Third-Person Effect in Communication // Public Opinion Quarterly, 47. 1983, pp. 1-15.

[2] Luhmann N. Society as a Social System. Moscow: Logos, 2004, p. 70 .

[3] Ibid., p. 47.

[4] Shultzman P.E. The Problem of Spectacle in the Context of Screen Culture // Journal of Moscow University. Series 10. Journalism. - 2011. - № 1, p. 247

[5] Baudrillard J. Requiem for the Media // Poetics and Politics. Almanac of the Russian-French Centre for Sociology and Philosophy of the Institute of Sociology of the Russian Academy of Sciences. Moscow: Institute of Experimental Sociology, St. Petersburg: Aleteia, 1999, p. 224.

[6] Chistyakova O. Philosophical-Anthropological Meanings of Postmodernism: "Mediatizing" Human // Proceedings of the International Conference on Contemporary Education, Social Sciences and Humanities. Advances in Social Science, Education, and Humanities Research (ICCESSH 2016). Volume 74. Paris: Atlantis Press, 2016, pp. 637-642

[7] Luhmann, N. The Reality of the Mass Media. M: Praxis, 2005.

[8] Epstein, E.J. News from Nowhere: Television and News. N.Y.: 1973.
[9] Rancière J. The Emancipated Spectator, Verso. New York, 2011, p. 96. 